\title{
Protein and phosphoprotein levels in glioma and adenocarcinoma cell lines grown in normoxia and hypoxia in monolayer and three-dimensional cultures
}

Victor A Levin ${ }^{1 *}$, Sonali Panchabhai ${ }^{1}$, Li Shen ${ }^{2}$ and Keith A Baggerly ${ }^{2}$

\begin{abstract}
Background: Three dimensional (3D) growths of cancer cells in vitro are more reflective of in situ cancer cell growth than growth in monolayer (2D). The present study is designed to determine changes in protein and phosphoprotein that reflect adaptation of tumor cells to 3D as compared to 2D. Since relative hypoxia is a common feature of most solid tumors, the present study also aims to look at the impact of transition from normoxia to hypoxia in these two growth conditions.
\end{abstract}

Results: Using reverse-phase protein arrays, we compared levels of 121 different phosphorylated and nonphosphorylated proteins in 5 glioma and 6 adenocarcinoma lines under conditions of 3D and monolayer culture in normoxia and hypoxia. A three-way analysis of variance showed levels of 82 antibodies differed between media (2D vs. 3D) and 49 differed between treatments (hypoxia vs. normoxia). Comparing 2D to 3D growth, 7 proteins were commonly (i.e., > 50\% of tumors) elevated in 3D: FAK, AKT, SrC, GSK3 $\alpha \beta$, TSC2, p38, and NF $\kappa \beta$ p 65 . Conversely, 7 other proteins are commonly decreased: ATRIP, ATR, $\beta$-catenin, BCL-X, cyclin B1, Egr-1, and HIF-1 $\alpha$. Comparing normoxia to hypoxia, only NCKIPSD was commonly elevated in hypoxia; 6 proteins were decreased: cyclin B1, 4EBP1(Ser65), c-Myc, SMAD3(Ser423), S6(Ser235), and S6(Ser240). Hypoxia affected glioma cell lines differently from adenocarcinoma cell lines: 8 proteins were increased in gliomas (BAX, caspase 7, HIF-1 $\alpha, c-J U N$, MEK1, PARP 1 cleaved, Src, and VEGFR2) and none in adenocarcinomas.

Conclusions: We identified subsets of proteins with clearly concordant/discordant behavior between gliomas and adenocarcinomas. In general, monolayer to 3D culture differences are clearer than normoxia to hypoxia differences, with anti-apoptotic, cytoskeletal rearrangement and cell survival pathways emphasized in the former and mTOR pathway, transcription, cell-cycle arrest modulation, and increased cell motility in the latter.

Keywords: glioblastoma, breast cancer, ovarian cancer, pancreatic cancer

\section{Background}

Cancer growth and invasion reflect many genetic and molecular events. These changes cannot be easily defined in situ, because (a) many factors are difficult to reproduce outside the host and (b) simplifications made to define variables with precision can create artifacts. In this and a prior study [1] we address a part of this

\footnotetext{
* Correspondence: vlevin49@comcast.net

'Department of Neuro-Oncology, The University of Texas MD Anderson Cancer Center, Houston, TX, USA

Full list of author information is available at the end of the article
}

problem. Specifically, we attempt to separate results due to a biological change of interest, the transition from normoxia to hypoxia, from those potentially induced by a simplification of the measurement process, growth in monolayer instead of in three dimensional cultures (3D). We have made other simplifications (e.g., using cell lines as opposed to primary cultures), so we are not perfectly "mimicking" disease conditions. Rather, we are focusing on effects of one specific simplification and outlining an approach that could be used more widely.

\section{Biomed Central}


The importance of hypoxia to our understanding of tumor growth is based on the premise that all tumors, at some time, exhibit reduced oxygen delivery to the respiring neoplastic and stromal cells. This can be microscopic or macroscopic but can lead to proteome changes in neoplastic and stromal cells leading to impaired neoplastic growth through molecular mechanisms, resulting in cellular quiescence, differentiation, apoptosis, and necrosis [2,3] and activation of genes, transcription factors, proteins, and cytokine signals that can lead to regional tumor defensive strategies such as angiogenesis, anaerobic glycolysis, locomotion (invasion/ metastasis), as well as tumor-specific survival strategies of apoptosis/autophagy $[4,5]$. These hypoxia-induced changes have presented challenges for cytotoxic chemotherapy and, likely, will do so for many targeted therapies. In addition, hypoxia diminishes the effectiveness of radiation therapy, in many cases, more for gliomas than for adenocarcinomas [6,7]. Thus, we hoped that being able to compare and contrast protein and phosphoprotein changes in glioma and adenocarcinoma cells might help design better treatment strategies for gliomas in the future.

The importance of studying protein changes in 3dimensional (3D) growth is also important since a feature of malignant cells is their ability to grow in 3 dimensions (3D) as spheroids and colonies. This observation has led to greater study of tumors in $3 \mathrm{D}$, as it is closer to in situ growth [8-11] even though it lacks many of the supporting extracellular systems (e.g., endothelial cells and capillaries, supporting matrices, cytokines, etc.). In addition, it has been observed that cancer cell lines grown in 2D and 3D culture respond differently to radiation and cytotoxic drugs [12-14]. Why do cell lines exhibit this differential behavior? Oxygenation of tumor cells also varies with $3 \mathrm{D}$ growth as cells grow distant from oxygen and nutrients, whether tumor cells are in $3 \mathrm{D}$ culture $[15,16]$ or part of an in situ tumor $[3,7,17,18]$. Most studies of hypoxia in tumor cells have utilized 2D cultures $[19,20]$.

In this study we begin to address the following questions. What protein and phosphoprotein changes reflect adaptations of tumor cells to 3D growth compared to $2 \mathrm{D}$ growth? What changes reflect adaptations from normoxia to hypoxia? Do tumor cells from high-grade glioma cell lines respond differently to $3 \mathrm{D}$ growth than adenocarcinoma cell lines? When exposed to relative hypoxic (aka microaerophilic) conditions, are changes in protein and phosphoprotein levels more affected by growth in $3 \mathrm{D}$ culture than they are by hypoxia?

In this study, we examine levels of 121 phosphorylated and non-phosphorylated proteins using reverse-phase protein array (RPPA) [1] technology. We examine these levels in eleven cell lines (including both gliomas and adenocarcinomas) under all combinations of media (2D and 3D) and growth conditions (normoxia and hypoxia), allowing us to properly relate changes to causes.

\section{Results and discussion}

Analysis using ANOVA (Three-Way Analysis of Variance)

Our qualitative findings can be inferred from the pvalue plots presented in Figure 1. Visual inspection of the distributions of p-values obtained for each ANOVA term (treatment, growth condition, cell line of origin, potential interaction between treatment and growth condition) clearly showed numbers of small p-values far greater than we would expect by chance for treatment, medium, and cell line, but not for the treatment-medium interaction (Figure 1). The cell line term is a nuisance factor, so we focused our attention on the individual effects of treatment and medium.

To account for multiple testing, we fit both distributions of p-values with beta-uniform mixture (BUM) models ${ }^{5}$ and chose cutoffs to target false discovery rates (FDRs) of $5 \%$ and $1 \%$. The extent of change (the height of the peak) is much more extensive for the shift from $2 \mathrm{D}$ to $3 \mathrm{D}$ than for the shift from normoxia to hypoxia. The corresponding plot for interaction terms here shows just a few significant alterations, suggesting that assessments of changes due to oxygenation conditions made in $2 \mathrm{D}$ are largely preserved in $3 \mathrm{D}$, answering our primary question. However, the amount of change we see associated with the 2D-to-3D transition is so large that we feel quite uneasy about generalizing measurements from $2 \mathrm{D}$ in general without explicit testing. To determine what changes were "robust," we trichotomized residual terms for each effect (after correcting for others) by assigning scores of 1 (top 25\%), -1 (bottom $25 \%$ ), and 0 (all others), and summed these values by cell line or antibody, which is an approach we found useful in an earlier study [1]. We also used these sums to look for differences between gliomas and adenocarcinomas. No proteins showed a significant interaction between culture conditions and treatment in any cell line at the $5 \%$ FDR.

\section{Comparison of 2D and 3D Growth}

The comparisons that follow are the product of an aggregate analysis across 11 cell lines and 4 growth conditions focusing on the protein differences between 2D and $3 \mathrm{D}$ culture conditions. According to the BUM plots, 82 proteins were significantly different at a $5 \%$ FDR. Figures 2 and 3 show (a) the 3D-2D (change from 2D to $3 \mathrm{D})$ sum scores with a focus on protein values from the ANOVA for proteins with p-values $<0.05$, (b) the associated estimated fold changes in expression (negative values indicate expression was higher in 2D cultures), and (c) trichotomized scores for individual protein 


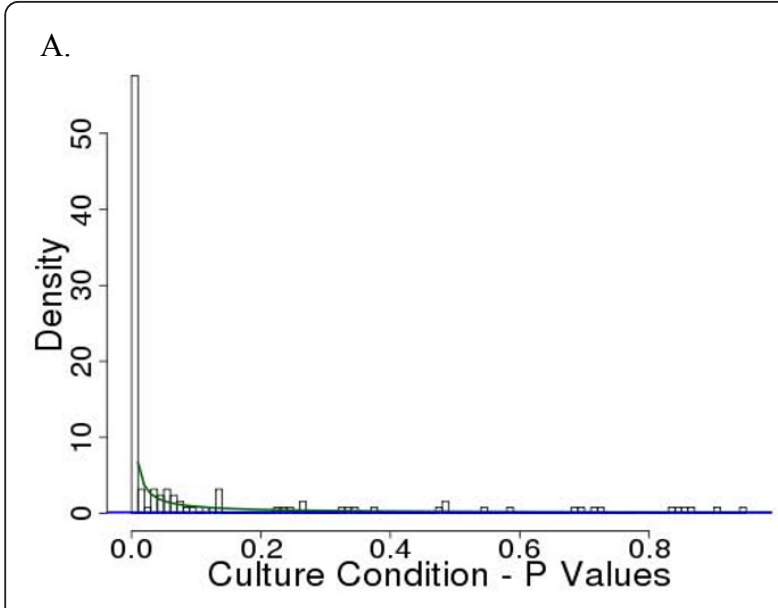

B.

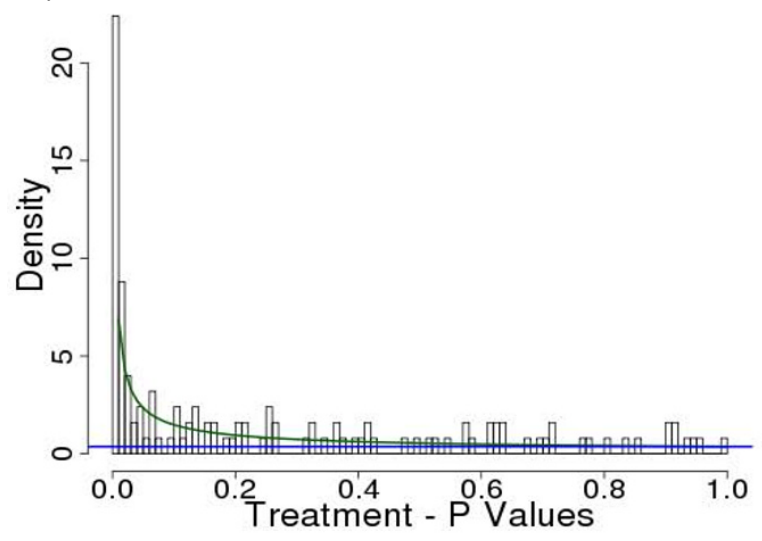

C.

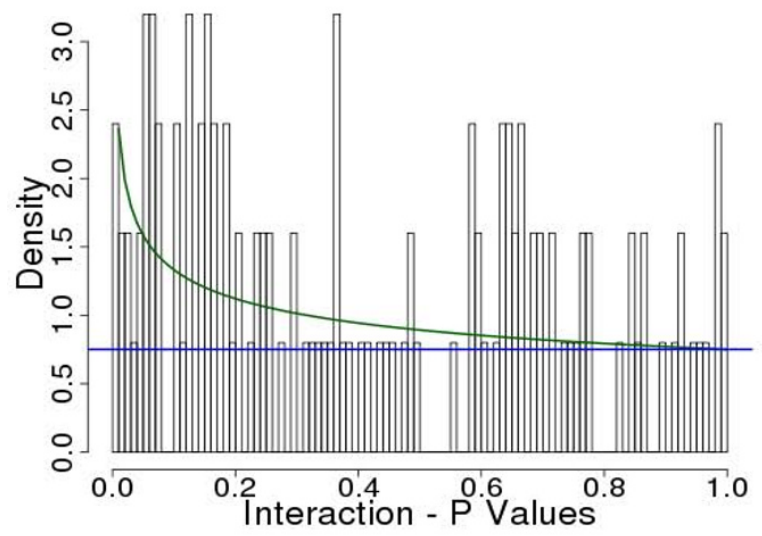

Figure 1 Histogram showing the distribution of $p$-values from the feature-by-feature three-way ANOVAs. Superimposed curves represent fits of the BUM models for (A) medium ( $2 \mathrm{D}$ and $3 \mathrm{D}$ ), (B) treatment (hypoxia and normoxia), and (C) interaction between medium and treatment.

samples, broken down to show results for individual gliomas or adenocarcinomas (for all values see Additional file 1). Figures 2 and 3 entries are sorted by fold change, and overall sums of the robust scores by cell line are given at the bottom of the table. We also show the aggregate glioma and adenocarcinoma behavior by indicating whether the robust scores in a category showed consistent values for at least $50 \%$ of the samples examined. The glioma cell line most consistently changed by 3D-2D growth conditions was U87, with an average sum score across hypoxic/normoxic conditions of $-18.5((-17+-20) / 2)$ indicating protein and phosphoprotein down-regulation as conditions shift from $2 \mathrm{D}$ to $3 \mathrm{D}$. By contrast, U251 ((14+-1)/2) and LN229 ((14+-1)/2) both showed general up-regulation of proteins when moving from $2 \mathrm{D}$ to $3 \mathrm{D}$, though these gains were concentrated in the hypoxic conditions. For the adenocarcinomas, SKOV3 showed the greatest down regulation, with an average sum score of-20 $((-22+-18) / 2)$, while MDA231 showed the greatest up regulation, with an average sum score of $19((14+24 / 2))$.

Qualitative examination of Figures 2 and 3 shows that as a group, adenocarcinoma cell lines had 1.6 times more -1 sum scores and 2.0 times more +1 sum scores than glioma cell lines. However, approximately 32 proteins showed parallel changes in adenocarcinoma and glioma cell lines. The breakdown of these 32 proteins that moved in parallel in $>50 \%$ of glioma and $>50 \%$ of adenocarcinoma cell lines are as follows:

1) Levels of 7 proteins were lower in $3 D$ than $2 D$ cultures for the two groups: ATRIP, ATR, $\beta$-catenin, BCL-X, cyclin B1, Egr-1, and HIF-1 $\alpha$;

2) 18 proteins showed no grossly consistent differences: AIB1, AR, ATR(Ser428), BCL2, BCL-XL, caspase 3, EGFR(Tyr992), 4EBP1(Ser65), LKB1, MGMT, p85 PI3K, p90RSK(Thr359), PCNA, PTCH, Rab25, Stat6(Tyr694), Stat5(Tyr694) and YY1; and

3) Levels of 7 proteins were higher in $3 \mathrm{D}$ than $2 \mathrm{D}$ cultures: AKT, FAK, GSK3 $\alpha \beta($ Ser21), NF $\kappa \beta$ p 65 (Ser536), p38(Thr180), c-Src(Tyr418), and TSC2 (Thr1462).

In addition to the protein changes above, differences were seen between glioma and adenocarcinoma cell lines grown in 3D and 2D cultures. In glioma cell lines, protein or phosphoprotein levels of Stat3(Thr727) and COX2 were also higher in $3 \mathrm{D}$ cultures, whereas in adenocarcinoma lines, additional protein increases were seen in 14-3-3-Z, TAU, ACC(Ser79), annexin, caspase 7, FOXO3, MAPK(Thr202), p70S6K, B-RAF, PARP, and PDK1(Ser241). In glioma cell lines, lower protein level in $3 \mathrm{D}$ cultures was seen only for cyclin D1, MSH2, Rb, S6(Ser235), and S6(Ser240), whereas in adenocarcinoma lines, lower levels were seen in ER(Ser118), FOXO3 $\alpha$ (Ser318), c-Jun(Ser73), c-Jun, c-Myc(Thr58), c-Myc, Rb (Ser807), SMAD3(Ser423), Src(Tyr527), Stat3, and VEGFR2. 


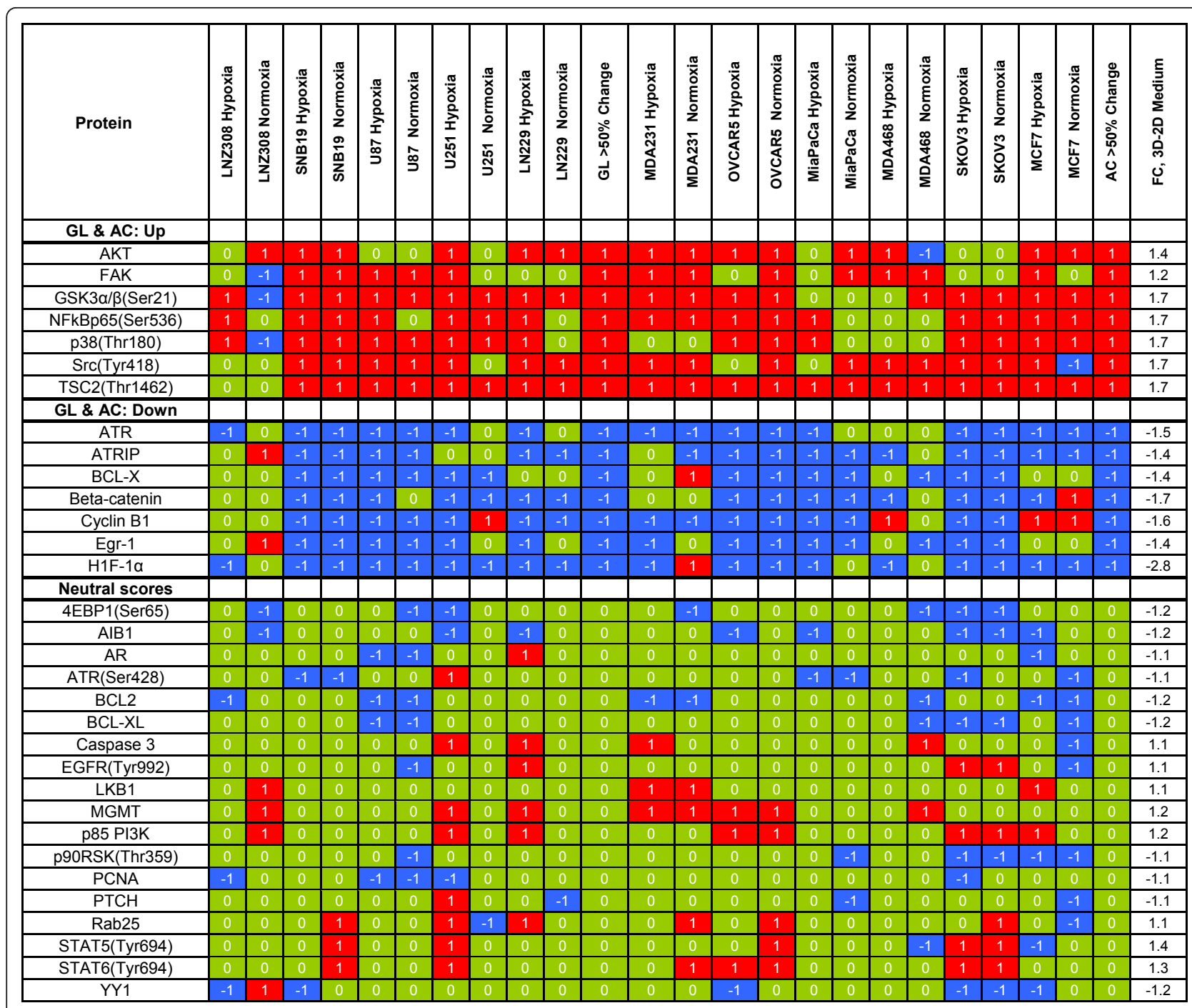

Figure 2 Protein changes from ANOVA of 3D-2D (monolayer to 3D) medium by cell line whether normoxic or hypoxic conditions for proteins with $\mathbf{p}$-value $<\mathbf{0 . 0 5}$. Proteins are ordered from based on the FC (fold change) and scored $-1,0$, or +1 , depending on quartile

distribution of raw antibody difference values $(-1$, blue, lowest quartile; +1 , red, highest quartile; 0 , green, others). Also shown is the score when $>50 \%$ of the total for glioma $(G L ; 6 / 10)$ and adenocarcinoma $(A C ; 7 / 12)$ values move in the same direction. The data is divided into six

groupings based on $>50 \%$ score $(+1,-1$, and 0$)$ for gliomas (GL) and adenocarcinomas (AC) together and separately as well as neutral and illdefined scores.

\section{Comparison of Hypoxic and Normoxic Growth}

The comparisons that follow are the product of an aggregate analysis across 11 cell lines and 4 growth conditions focusing on the protein differences between normoxia and hypoxia culture conditions. On the basis of the BUM plots, 50 proteins were significantly different in conditions of hypoxic and normoxic growth at a $5 \%$ FDR. Figure 4 focuses on (a) protein values from the ANOVA for proteins with p-values $<0.05$, (b) the associated estimated fold change (negative values indicate that expression was higher in normoxic cultures), and (c) trichotomized scores for individual samples, broken down to show results for individual glioma and adenocarcinoma cell lines (for all values see Additional file 2). Figure 4 entries are sorted by fold change, and overall sums of the robust scores by cell line are given at the bottom. We have also shown aggregate glioma and adenocarcinoma behavior by indicating whether the robust scores in a category showed consistent values for at least $50 \%$ of the samples examined. Figure 4 shows that no glioma cell line showed a consistent decrease in sum scores between normoxic and hypoxic cultures, but some did increase. Protein and phosphoprotein sum scores were higher in hypoxic cultures for U87, LN229, and U251 cells, with sums of $+12,+10.5$, and +9 , respectively. For the adenocarcinoma cell lines, SKOV3 had 


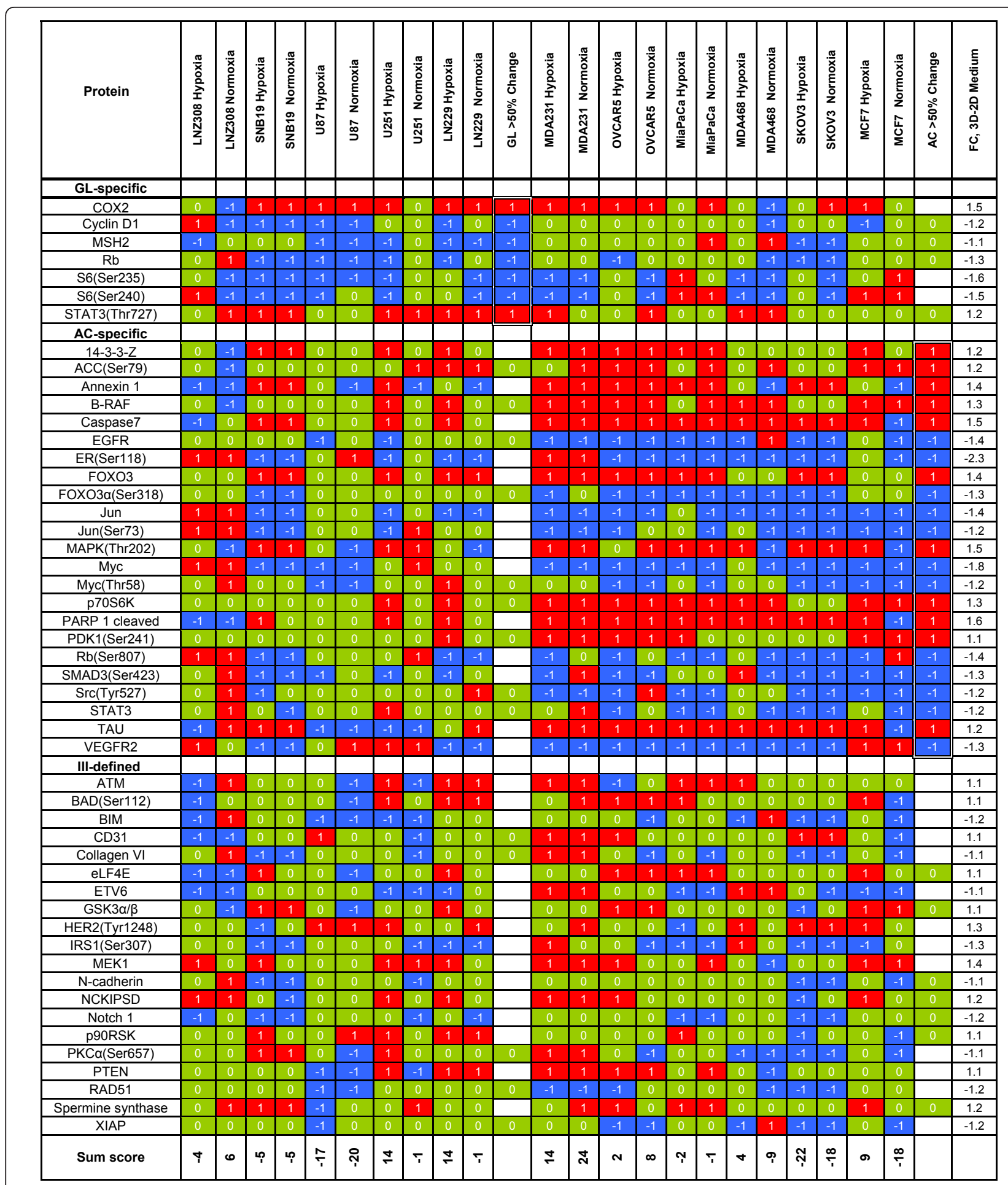

Figure 3 Protein changes from ANOVA of 3D-2D (monolayer to 3D) medium by cell line whether normoxic or hypoxic conditions for proteins with $\mathbf{p}$-value $<\mathbf{0 . 0 5}$. Proteins are ordered from based on the $F C$ (fold change) and scored -1 , 0 , or +1 , depending on quartile

distribution of raw antibody difference values ( -1 , blue, lowest quartile; +1 , red, highest quartile; 0 , green, others). Also shown is the score when $>50 \%$ of the total for glioma $(\mathrm{GL} ; 6 / 10)$ and adenocarcinoma $(\mathrm{AC} ; 7 / 12)$ values move in the same direction. The data is divided into six groupings based on $>50 \%$ score $(+1,-1$, and 0$)$ for gliomas $(G L)$ and adenocarcinomas (AC) together and separately as well as neutral and illdefined scores. The Sum Score at the bottom of the figure is the summed values for columns in figures 2 and 3. 
the most down regulation with an average sum score of $-22.5[(-13+-32) / 2]$, while OVCAR5 and MDA231 showed the greatest up regulation, with average sum scores of 13.5 and 10 , respectively.

Qualitative examination of Figure 4 shows that, as a group, glioma cells lines had 1.7 times more -1 sum scores and 10 times more +1 sum scores than adenocarcinoma cell lines. However, 17 proteins showed parallel changes in adenocarcinoma and glioma cell lines, as follows:

1) Levels of 6 proteins were lower in hypoxic conditions than in normoxic conditions in the two groups: cyclin B1, 4EBP1(Ser65), c-Myc, SMAD3(Ser423), S6 (Ser235), and S6(Ser240);

2) 10 proteins showed no grossly consistent differences: caspase 3, EGFR(Tyr1173), elF4E, FAK, JNK2, MGMT, PDK1, spermine synthetase, TSC2 (Thr1462), and VASP; and

3) 1 protein was higher in hypoxic cultures: NCKIPSD.

In addition to the protein changes reported above, differences were seen between glioma and adenocarcinoma cell lines grown in hypoxia and those grown in normoxia. In glioma cell lines, protein or phosphoprotein levels were also higher for BAX, caspase 7 , HIF-1 $\alpha$, cJUN, MEK1, cleaved PARP, Src(Tyr527), and VEGFR2, whereas no additional protein increases were seen in adenocarcinoma lines. In glioma cell lines, hypoxia caused declines in the expression of AR, ATR(Ser428), cyclin $\mathrm{D} 1$, and $\mathrm{Rb}(\mathrm{Ser} 807)$, whereas no additional protein decreases were seen in adenocarcinoma lines.

\section{Relevance of Protein Changes}

In order to better understand the implications of the protein changes we observed, we used the Weizmann Institute of Science site http://www.genecards.org, Cell Signaling Technology http://www.cellsignal.com/, and TOCRIS Bioscience http://www.tocris.com/ to annotate the gene-associated proteins studied. Our interpretation of protein interactions and their implications is subject to a caveat: we only have an incomplete understanding of the non-linear interactions among signaling proteins, and, therefore, can only surmise functional significance from the protein changes we observed.

\section{$2 D$ to $3 D$ Changes Overall}

While there are a number of ways that our data could be analyzed and interpreted, we analyzed the aggregate data for $2 \mathrm{D}$ to $3 \mathrm{D}$ culture regardless of whether cells were grown in normoxia or hypoxia. From these data we concluded that the majority of cancer cell lines share some proteins that are increased to enable 3D growth and proteins that are reduced to minimize non-vital cell functions and focus. For the sake of discussion, and using available pathway analyses, we propose some relationships for the major protein changes observed for both glioma and adenocarcinoma cell lines (Figure 5). Increasing AKT can tend to decrease apoptosis and increase insulin stimulated protein synthesis by phosphorylating TSC2 (Thr1462) and activating mTOR signaling and phosphorylating 4E-BP1 and RPS6KB1. Increasing FAK, a substrate for $\mathrm{C}-\mathrm{Src}$, is important in cell migration and mobility, and appears to be important in shifting cancer cells from 2D to 3D growth. Similarly, increases in GSK $3 \alpha / \beta$ should help in cell division and motility through its ability to phosphorylate signaling proteins, transcription factors, and structural proteins, all of which are needed to support 3D growth. Increases in NF $\kappa \beta$ and p38, a MAP kinase family member, have effects on proliferation and transcriptional regulation through their ability to respond to cytokines and extracellular environmental stress, conditions that may be an advantage to cancer cells seeking to achieve 3D growth. Contra wise, the proteins levels that decreased suggested that these cancer cells did not need to protect themselves against DNA damage (ATR and ATRIP) or apoptosis (BCL-X and cyclin B1) or maintain cell adhesion on a plastic surface ( $\beta$-catenin). The paradoxical decrease in transcriptional control of mitogenesis and differentiation (Egr-1) and HIF-1 $\alpha$ is problematic. Even if we look at $2 \mathrm{D}$ to $3 \mathrm{D}$ growth separately for normoxia and hypoxia (see Additional File 1 for details) HIF1- $\alpha$ paradoxically decreased. Since HIF- $1 \alpha$ did go up in the glioma lines in response to the shift from normoxia to hypoxia, it is possible that cells adapting to $3 \mathrm{D}$ growth in AlgiMatrix 3D Culture System or as a normal survival mechanism reduce $\mathrm{HIF}-1 \alpha$ protein or that HIF- $1 \alpha$ degradation occurred under when cells were grown in the AlgiMatrix 3D Culture System in a manner similar to the ubiquitination seen with hypoxia-associated factor [21]. Thus, while we are confident of our finding, we are not sanguine as to its basis at this time since we did not measure the level of HIF- $2 \alpha$ in our RPPA study. We have made our entire database available for others to mine (see Additional file 1 for details) in the expectation that scientists will find these data helpful and, possibly, better explain these findings.

$2 D$ to $3 D$ Changes Specific to Gliomas or Adenocarcinomas In addition to the general changes, there were gliomaspecific changes in protein levels. Increases in Stat 3 suggest that glioma cells, responding to cytokines and growth factors, activate transcription to help establish $3 \mathrm{D}$ growth. Increase in inducible COX2 is known to occur in gliomas and may, through prostanoid biosynthesis, enhance mitogenesis. There were also specific changes in adenocarcinoma lines. Increases may reflect increased signaling activities and direct effects on cell adhesion and anchorage-independent growth (14-3-3-Z), 


\begin{tabular}{|c|c|c|c|c|c|c|c|c|c|c|c|c|c|c|c|c|c|c|c|c|c|c|c|c|c|}
\hline Protein & $\begin{array}{l}\text { N } \\
\infty \\
\varnothing^{\circ} \\
N \\
\mathbf{N} \\
\mathbf{z}\end{array}$ & $\begin{array}{l}0 \\
\text { p } \\
\text { o } \\
\tilde{N} \\
\mathbf{N} \\
\text { z }\end{array}$ & $\begin{array}{l}\text { N } \\
\frac{0}{0} \\
\frac{m}{2}\end{array}$ & 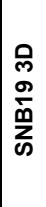 & $\begin{array}{l}\text { N } \\
\text { o } \\
\stackrel{\infty}{\supset}\end{array}$ & 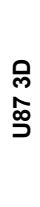 & $\begin{array}{l}\text { N } \\
\stackrel{5}{N} \\
\text { ปn }\end{array}$ & 足 & $\begin{array}{l}\text { N } \\
\text { న్ } \\
\text { ָ̦ }\end{array}$ & $\begin{array}{l}\text { O } \\
\text { న్ } \\
\text { ָ̇ }\end{array}$ & 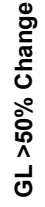 & 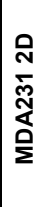 & 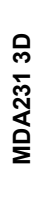 & 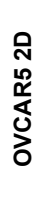 & 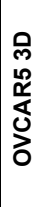 & 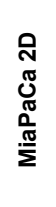 & 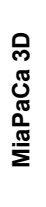 & 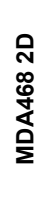 & 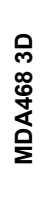 & $\begin{array}{l}\text { Oิ } \\
\text { วิ } \\
\text { ơ } \\
\text { w }\end{array}$ & 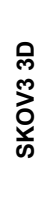 & 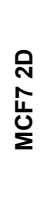 & $\begin{array}{l}0 \\
\stackrel{0}{U} \\
\frac{0}{\Sigma}\end{array}$ & 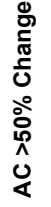 & 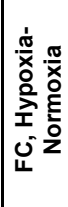 \\
\hline \multicolumn{26}{|l|}{ GL \& AC: Up } \\
\hline NCKIPSD & 0 & -1 & 0 & 1 & 1 & 1 & 0 & 1 & 1 & 1 & 1 & 1 & 1 & 1 & 1 & 1 & 0 & 1 & 0 & 0 & -1 & 0 & 1 & 1 & 1.2 \\
\hline \multicolumn{26}{|l|}{ GL \& AC: Down } \\
\hline S6(Ser240) & -1 & 1 & -1 & -1 & -1 & -1 & -1 & -1 & -1 & -1 & -1 & -1 & -1 & -1 & -1 & -1 & 1 & -1 & -1 & -1 & 0 & -1 & -1 & -1 & -2.3 \\
\hline S6(Ser235) & -1 & 1 & -1 & -1 & -1 & -1 & -1 & -1 & -1 & -1 & -1 & -1 & -1 & -1 & 0 & -1 & 1 & -1 & -1 & -1 & 0 & -1 & -1 & -1 & -1.9 \\
\hline Cyclin-B1 & -1 & -1 & -1 & -1 & -1 & -1 & -1 & -1 & -1 & -1 & -1 & 1 & 1 & -1 & 0 & 0 & -1 & -1 & -1 & -1 & -1 & -1 & -1 & -1 & -1.5 \\
\hline C-Myc & 1 & 0 & -1 & -1 & -1 & -1 & -1 & -1 & -1 & -1 & -1 & 1 & 1 & 0 & 0 & -1 & -1 & -1 & -1 & -1 & -1 & 0 & -1 & -1 & -1.3 \\
\hline SMAD3(Ser423) & 0 & -1 & -1 & -1 & 0 & -1 & 0 & -1 & -1 & -1 & -1 & 1 & -1 & 1 & -1 & -1 & -1 & -1 & 0 & 0 & -1 & 0 & -1 & -1 & -1.2 \\
\hline 4EBP1(Ser65) & -1 & 1 & -1 & -1 & -1 & 0 & -1 & -1 & -1 & 0 & -1 & -1 & 0 & -1 & -1 & 0 & 0 & -1 & 0 & -1 & -1 & -1 & -1 & -1 & -1.1 \\
\hline \multicolumn{26}{|l|}{ Neutral scores } \\
\hline Caspase3 & 0 & 0 & 0 & 0 & 1 & 0 & 0 & 1 & 0 & 1 & 0 & 0 & 0 & 0 & 0 & 0 & 0 & 0 & 0 & 0 & -1 & -1 & 1 & 0 & 1.1 \\
\hline EGFR(Tyr1173) & 0 & 0 & 0 & 0 & 0 & 1 & 0 & 1 & 0 & 1 & 0 & 0 & 0 & 0 & 0 & 1 & 0 & 1 & 1 & 0 & 0 & 0 & 1 & 0 & 1.2 \\
\hline eLF4E & 0 & 0 & 0 & 1 & 0 & 1 & 0 & 1 & 0 & 1 & 0 & 0 & 0 & 0 & 1 & 0 & 1 & -1 & 0 & 0 & 0 & -1 & 1 & 0 & 1.1 \\
\hline FAK & 0 & 1 & 0 & 0 & 1 & 0 & 0 & 1 & 0 & 0 & 0 & -1 & 0 & 0 & 0 & 1 & 0 & 0 & 0 & 0 & -1 & -1 & 1 & 0 & 1.1 \\
\hline JNK2 & 0 & 0 & 0 & 0 & 0 & 0 & 0 & 1 & 0 & 1 & 0 & 0 & 0 & 1 & 1 & 0 & 0 & -1 & 0 & 0 & 0 & 0 & 1 & 0 & 1.1 \\
\hline MGMT & 0 & 0 & 0 & 1 & 0 & 1 & 0 & 1 & 0 & 1 & 0 & 1 & 0 & 0 & 0 & 0 & 0 & 1 & -1 & 0 & -1 & 0 & -1 & 0 & 1.1 \\
\hline PDK1 & 0 & -1 & 0 & 0 & 0 & 1 & 0 & 1 & 0 & 1 & 0 & 0 & 0 & 0 & 1 & 0 & 0 & 0 & 0 & -1 & -1 & -1 & 1 & 0 & 1.1 \\
\hline Spermine-synthase & 0 & -1 & 0 & 1 & 1 & 0 & 0 & 0 & 0 & 1 & 0 & 1 & 0 & 1 & 1 & 0 & $\overline{0}$ & 0 & 0 & 0 & 0 & 0 & 1 & 0 & 1.1 \\
\hline TSC2(Thr1462) & -1 & -1 & 0 & 1 & 0 & 0 & 0 & 1 & 0 & 0 & 0 & 1 & 0 & 1 & 0 & 0 & 0 & 0 & 1 & 1 & 0 & 0 & 1 & 0 & 1.1 \\
\hline VASP & 0 & 0 & 0 & 1 & 0 & 1 & 0 & 1 & 0 & 1 & 0 & 0 & 1 & 0 & 0 & 1 & 0 & 0 & 0 & 0 & -1 & -1 & 1 & 0 & 1.1 \\
\hline \multicolumn{26}{|l|}{ GL-specific } \\
\hline $\mathrm{AR}$ & -1 & -1 & -1 & -1 & 0 & 0 & -1 & -1 & -1 & 1 & -1 & 0 & 0 & 0 & 0 & 0 & 0 & -1 & 0 & 0 & -1 & -1 & -1 & 0 & -1.1 \\
\hline ATR(Ser428) & 0 & -1 & 0 & -1 & -1 & -1 & 0 & -1 & 0 & -1 & -1 & 0 & 1 & 0 & -1 & 0 & 0 & 0 & 0 & -1 & -1 & -1 & -1 & & -1.1 \\
\hline BAX & 0 & 1 & 1 & 1 & 0 & 0 & 0 & 1 & 1 & 1 & 1 & 0 & 0 & 1 & 1 & 0 & 0 & -1 & 0 & -1 & -1 & 0 & 1 & & 1.1 \\
\hline $\begin{array}{l}\text { Caspase } 7 \\
\end{array}$ & 1 & 0 & 1 & 1 & 1 & 1 & 0 & 1 & 0 & 1 & 1 & 0 & -1 & 1 & 1 & 0 & 1 & 0 & 0 & 0 & 0 & -1 & 1 & & 1.3 \\
\hline C-JUN & 1 & 1 & -1 & 1 & 1 & 1 & 0 & -1 & 1 & 1 & 1 & 1 & 1 & 1 & 1 & -1 & 0 & -1 & -1 & -1 & 0 & 1 & 1 & & 1.3 \\
\hline COX2 & 1 & 1 & 0 & 1 & 1 & 1 & 1 & 1 & 1 & 1 & 1 & 1 & -1 & 0 & 0 & 0 & 0 & -1 & 0 & 0 & -1 & 0 & 1 & 0 & 1.4 \\
\hline Cyclin-D1 & -1 & 1 & -1 & 0 & -1 & -1 & -1 & -1 & -1 & -1 & -1 & -1 & 0 & 0 & 0 & 0 & -1 & -1 & 0 & -1 & 0 & 0 & -1 & 0 & -1.2 \\
\hline H1F-1 $\alpha$ & 1 & 1 & 1 & -1 & 1 & -1 & 1 & -1 & 1 & -1 & 1 & 1 & -1 & -1 & -1 & 1 & 0 & 1 & 0 & -1 & -1 & 1 & 0 & & 1.5 \\
\hline MEK1 & -1 & 1 & 0 & 1 & 1 & 1 & 0 & 1 & 0 & 1 & 1 & 1 & 1 & -1 & 1 & 1 & 1 & -1 & -1 & 0 & 0 & 0 & 1 & & 1.2 \\
\hline PARP 1 cleaved & 1 & 0 & 1 & 1 & 1 & 1 & 0 & 1 & 0 & 1 & 1 & 0 & 1 & 1 & 1 & 1 & 1 & 0 & 0 & 0 & -1 & -1 & 1 & & 1.5 \\
\hline $\mathrm{Rb}($ Ser807) & -1 & -1 & -1 & -1 & -1 & -1 & -1 & -1 & -1 & -1 & -1 & 1 & 0 & 0 & -1 & -1 & -1 & -1 & -1 & 0 & 0 & 1 & -1 & & -1.4 \\
\hline Src(Tyr527) & 1 & -1 & 1 & 0 & 1 & 1 & 1 & 1 & 0 & 0 & 1 & 1 & 0 & 1 & 0 & 0 & 0 & 0 & 0 & 0 & 0 & -1 & 0 & 0 & 1.1 \\
\hline VEGFR2 & 0 & 1 & 1 & 1 & 1 & 0 & 1 & 1 & 1 & 1 & 1 & 1 & 0 & 1 & -1 & 1 & 0 & 0 & 0 & 1 & -1 & 1 & 1 & & 1.3 \\
\hline \multicolumn{26}{|l|}{ III-defined } \\
\hline 14-3-3-Z & 0 & 1 & 0 & 0 & 1 & 0 & 0 & 1 & 0 & 1 & 0 & -1 & 0 & 0 & 0 & 1 & 1 & 0 & 0 & 0 & -1 & -1 & 1 & & 1.1 \\
\hline 4EBP1 & 0 & -1 & 0 & 0 & 1 & 1 & 0 & 0 & 0 & 1 & & 0 & 0 & 0 & 0 & 1 & 1 & 1 & 0 & 1 & -1 & 0 & 1 & & 1.1 \\
\hline BCL-XL & 1 & 1 & 1 & 0 & 0 & 0 & 0 & 1 & 1 & 0 & 0 & 1 & 1 & 1 & 1 & 0 & 0 & 0 & 0 & -1 & -1 & 1 & 1 & & 1.2 \\
\hline CHK2(Thr68) & 0 & 0 & 0 & 0 & 0 & 1 & 0 & 1 & 1 & 1 & 0 & 1 & 0 & 1 & 1 & 0 & 1 & 1 & 0 & 0 & 0 & 0 & 1 & & 1.2 \\
\hline Collagen-VI & 0 & 0 & 0 & 1 & 0 & 1 & 0 & 1 & 1 & 0 & 0 & 0 & 0 & 1 & 1 & 0 & 0 & -1 & 0 & -1 & -1 & 0 & 1 & & 1.1 \\
\hline EGFR & 1 & 0 & 0 & 0 & 1 & 1 & 1 & 0 & 0 & 1 & & 0 & 0 & 1 & 0 & 0 & -1 & 1 & 0 & -1 & -1 & 0 & 1 & & 1.2 \\
\hline FAK(Tyr397) & 0 & 0 & 0 & 1 & 0 & 1 & 0 & 1 & 1 & 0 & 0 & 1 & 0 & 1 & 0 & 0 & 1 & 1 & 0 & 0 & -1 & 0 & 1 & & 1.1 \\
\hline FOXO3 & 0 & 0 & 0 & 1 & 0 & 0 & 0 & 1 & 1 & 1 & 0 & 1 & 1 & 1 & 1 & 0 & 1 & 0 & 0 & 0 & -1 & 0 & 1 & & 1.2 \\
\hline FOXO3 $\alpha($ Ser318) & -1 & -1 & 0 & 0 & 1 & 1 & 0 & 0 & 0 & 0 & 0 & 1 & 0 & 0 & 1 & 1 & 0 & 0 & 0 & 1 & -1 & 1 & 1 & & 1.1 \\
\hline HSP70 & 0 & 0 & 1 & 1 & 1 & 0 & 0 & 1 & 0 & 1 & & 0 & 0 & 0 & 1 & 0 & 0 & 0 & 0 & 0 & -1 & -1 & 1 & 0 & 1.1 \\
\hline $\mathrm{N}$-Cadherin & 1 & -1 & 0 & -1 & 1 & 1 & 0 & 1 & 0 & 0 & & 0 & 1 & 0 & 0 & -1 & 0 & 0 & 0 & 0 & 0 & -1 & 1 & 0 & 1.1 \\
\hline Notch 1 & 1 & -1 & 1 & 0 & 0 & 0 & 0 & 1 & 0 & 0 & 0 & 1 & 0 & 0 & 0 & 1 & 0 & 1 & 0 & -1 & -1 & 0 & 1 & & 1.1 \\
\hline Notch-3 & 0 & 0 & 1 & 0 & 1 & 0 & 0 & 1 & 0 & 1 & 0 & 0 & -1 & 1 & 1 & -1 & -1 & 1 & 0 & 0 & 0 & 1 & 0 & & 1.1 \\
\hline p85 PI3K & 0 & -1 & 0 & 0 & 0 & 0 & 0 & 1 & 0 & 1 & 0 & 0 & 0 & 0 & 0 & 1 & 1 & -1 & $\overline{0}$ & -1 & 0 & -1 & 1 & & 1 \\
\hline p90RSK & 0 & 0 & 0 & 1 & 1 & 1 & 0 & 1 & 0 & 1 & & 0 & 1 & 0 & 0 & 0 & 1 & 1 & 0 & 0 & -1 & 0 & 1 & & 1.2 \\
\hline PCNA & 1 & -1 & 0 & -1 & 0 & 0 & 0 & -1 & 1 & 0 & & 1 & 0 & 1 & 1 & 0 & 0 & 0 & 0 & 0 & -1 & 1 & 0 & 0 & 1.1 \\
\hline PTCH & 0 & 1 & 1 & 0 & 0 & 1 & 0 & 1 & -1 & 0 & & 0 & 0 & 1 & 0 & 0 & 0 & 0 & 0 & 0 & -1 & 0 & 1 & 0 & 1.1 \\
\hline Rab25 & 0 & 0 & 0 & 0 & 0 & 0 & 0 & 1 & 0 & 1 & 0 & 0 & -1 & 1 & 1 & 0 & -1 & 0 & 0 & 0 & -1 & 0 & 1 & & 1.1 \\
\hline STAT3 & 0 & -1 & 0 & 1 & 0 & 0 & 1 & 1 & 1 & 0 & & 1 & 1 & 1 & 0 & -1 & -1 & -1 & 0 & 0 & 0 & 0 & 1 & & 1.1 \\
\hline STAT3(Thr727) & -1 & -1 & -1 & -1 & 0 & 0 & 0 & 1 & 0 & 0 & & -1 & 0 & 0 & -1 & -1 & -1 & 0 & 0 & -1 & -1 & 0 & 0 & & -1.1 \\
\hline Sum score & - & A & o & 0 & $\simeq$ & $\simeq$ & ง & กิ & $m$ & $\stackrel{\infty}{\sim}$ & & $\stackrel{2}{5}$ & in & 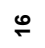 & $\mp$ & $m$ & $m$ & $\hat{\imath}$ & $\varphi$ & $\stackrel{m}{T}$ & ข్ & 운 & $\widetilde{N}$ & & \\
\hline
\end{tabular}

Figure 4 Protein changes from ANOVA of the hypoxia-normoxia by cell line, whether grown in 2D or 3D conditions for proteins with p-values $<\mathbf{0 . 0 5}$. The proteins are ordered based on the FC (fold change) and scored $-1,0$, or +1 depending on quartile distribution of raw antibody difference values $(-1$, blue, lowest quartile; +1 , red, highest quartile; 0 , green, others). Also shown is the score when $>50 \%$ of the total for glioma (GL; 6/10) and adenocarcinoma (AC; 7/12) values move in the same direction. The data is divided into five groupings based on $>50 \%$ score $(+1,-1$, and 0$)$ for gliomas and adenocarcinomas together and separately as well as neutral and ill-defined scores. 


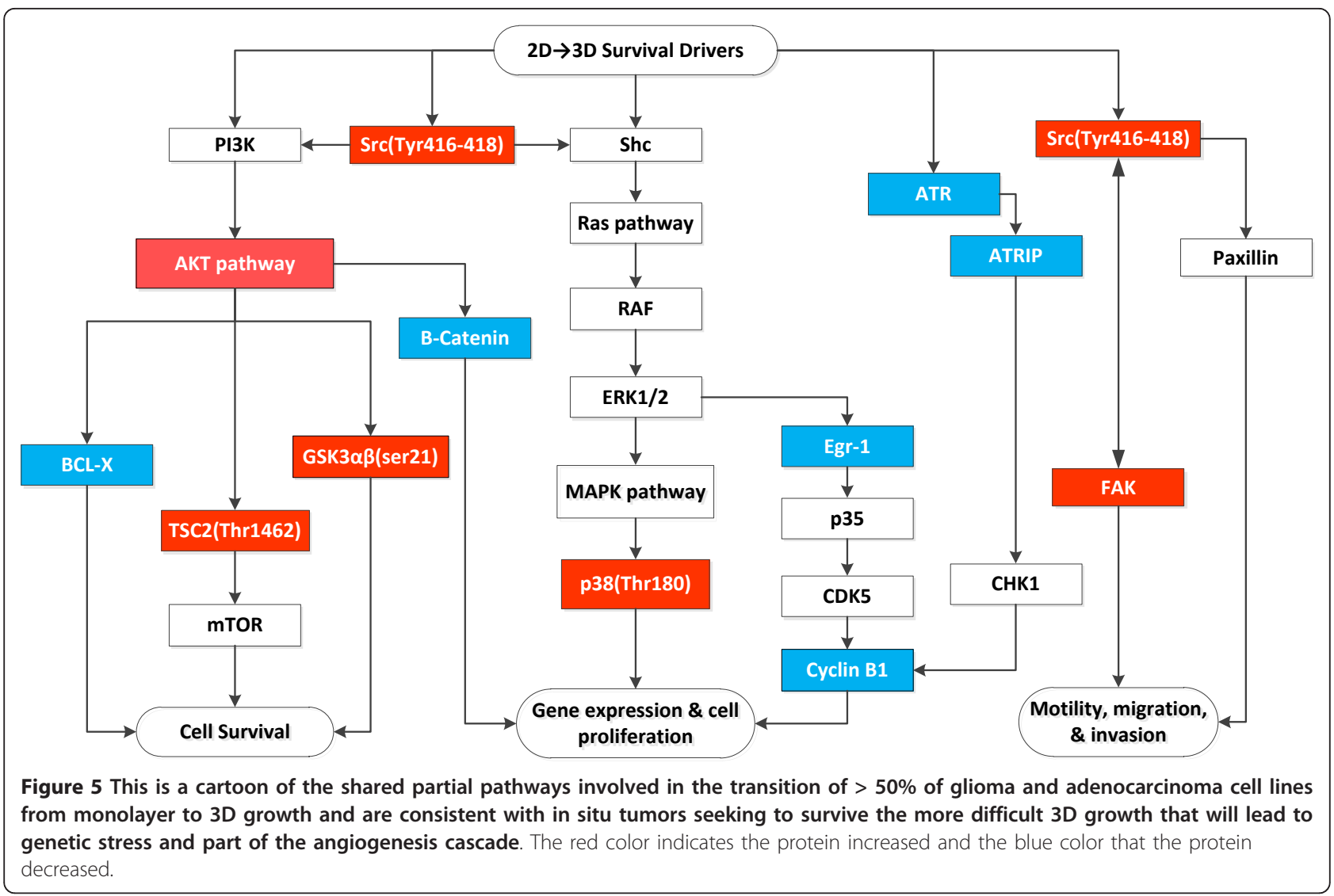

fatty acid synthesis (ACC), mediation of growth-regulated tyrosine kinases (annexin 1), regulation of MAPK/ ERK signaling (B-RAF), activation of apoptosis (caspase 7, FOXO3), and transcription regulation and proliferation (MAPK). Interestingly, TAU, a microtubulin-associated protein, is differentially expressed in the nervous system and was thought to be somewhat unique to the nervous system, but we found higher levels of TAU in adenocarcinoma cell lines. What this means is not clear, but, given its effect in the nervous system, it may function to stabilize cytoskeletal proteins and be part of signaling system to organize adenocarcinoma cells in a basal-antral position for glandular functions.

\section{Normoxia to Hypoxia Changes Overall}

Transitioning from normoxia to hypoxia, only 17 proteins move commonly among the glioma and adenocarcinoma cell lines. Interestingly, only one protein was elevated, NCKIPSD, a protein implicated in signal transduction as well as cell motility and stress fiber formation [22-27]. A relationship of the 6 proteins that decreased and the 1 protein that increased are depicted in Figure 6 . In general, hypoxia appeared to decrease protein synthesis through the mTOR pathway to reduce cell cycle progression while supporting motility and migration through NCKIPSD

\section{Normoxia to Hypoxia Changes Specific to Gliomas or Adenocarcinomas}

Glioma cell lines behave quite differently from adenocarcinoma cell lines when exposed to hypoxia. There are 8 increased proteins in gliomas (BAX, caspase 7 , HIF-1 $\alpha$, c-JUN, MEK1, PARP 1 cleaved Src, and VEGFR2) and none in adenocarcinomas (Figure 7). It appears that gliomas are more responsive (sensitive) to hypoxia than adenocarcinoma. Both pro-survival and pro-apoptotic pathways are activated and a balance between these two might determine the ultimate outcome of the cells. The observations in glioma are consistent with the literature [28-31].

However, the fact that HIF- $1 \alpha$ is not increased in adenocarcinoma cells is problematic with three possible explanations. 1) That hypoxic conditions were insufficient in the adenocarcinoma cell lines while sufficient in the gliomas to elicit activation of HIF- $1 \alpha$ based on the possibility that astrocytes are constitutively more sensitive and responsive to hypoxia in keeping with their function to protect neurons and this functionality carries over to the glioma (malignant astrocytoma) tumors studied. 2) HIF-1 $\alpha$ levels were constitutively up regulated (oncogenic) in the glioma lines independent of hypoxic effects. In an effort to answer this question, we 
compared each protein across cell lines and between glioma and adenocarcinoma groups from monolayer conditions. We found only 3 proteins that had a coefficient of variation of $>0.5$ and T-test $\mathrm{p}<0.05$, and they were AKT(ser473), AK(Thr308) and HIF-1 $\alpha$; they were higher in base value in the glioma lines than adenocarcinoma lines by 4.7-, 3.0-, and 2.6-fold. Since the cell lines were compared to themselves, with respect to change in protein level, under the various "treatment" conditions of 3D culture and hypoxia, the differences in absolute level did not have an adverse effect on the data we report in Figures 1, 2, 3 and 4). 3) The failure of HIF-1 $\alpha$ to increase with hypoxia in adenocarcinoma lines could be these cell lines mediate the hypoxia response mainly by HIF- $2 \alpha$ orHIF- $3 \alpha$. Since we did not measure these proteins in our studies, we cannot test this hypothesis.

\section{Conclusion}

We examined the proteins associated with each transition to see if there was clear involvement of specific pathways. Our findings were mixed. The changes are broad and extensive, not clearly concentrated in one area. During transition from 2D to 3D growth we see large changes at the protein level and AKT and MAPK pathways are mainly activated to provide survival and anticipated a need for angiogenesis in 3D. In hypoxia as compared to normoxia, the mTOR pathway is downregulated. Also during hypoxia, when glioma cell lines are compared to adenocarcinomas, we infer that gliomas are much more responsive to hypoxia than adenocarcinomas as evident from the simultaneous apoptotic and pro-survival pathway activation.

We wish our experiments had definitively exposed a new therapeutic strategy for high-grade glioma and/or adenocarcinomas. What we have learned, however, is more tentative and incomplete. The mTOR pathways appeared to be down regulated in hypoxia in the current study and under conditions of starvation from our previous study. If mTOR pathways are normally down-regulated in tumor hypoxia, drug inhibitors of the mTOR pathway may not be a successful treatments for highgrade gliomas as the target may already be depressed, a conclusion supported by current clinical trials of mTOR inhibitors in glioblastoma patients [32-35].

Our data are available on the web. We hope others will look at our data and approach and make further observations to develop better chemotherapy strategies in the future.

\section{Methods}

\section{Cell Lines}

We used 11 established cell lines in this study. Six adenocarcinomas were comprised of three human breast cancer cell lines (MCF7, MDA231, MDA468), gifts from Francisco Esteva (MD Anderson); a human pancreatic carcinoma (MiaPaCa), a gift from Kapil Mehta (MD Anderson); and two human ovarian carcinomas (OVCAR5 and SKOV3), purchased from the American Type Culture

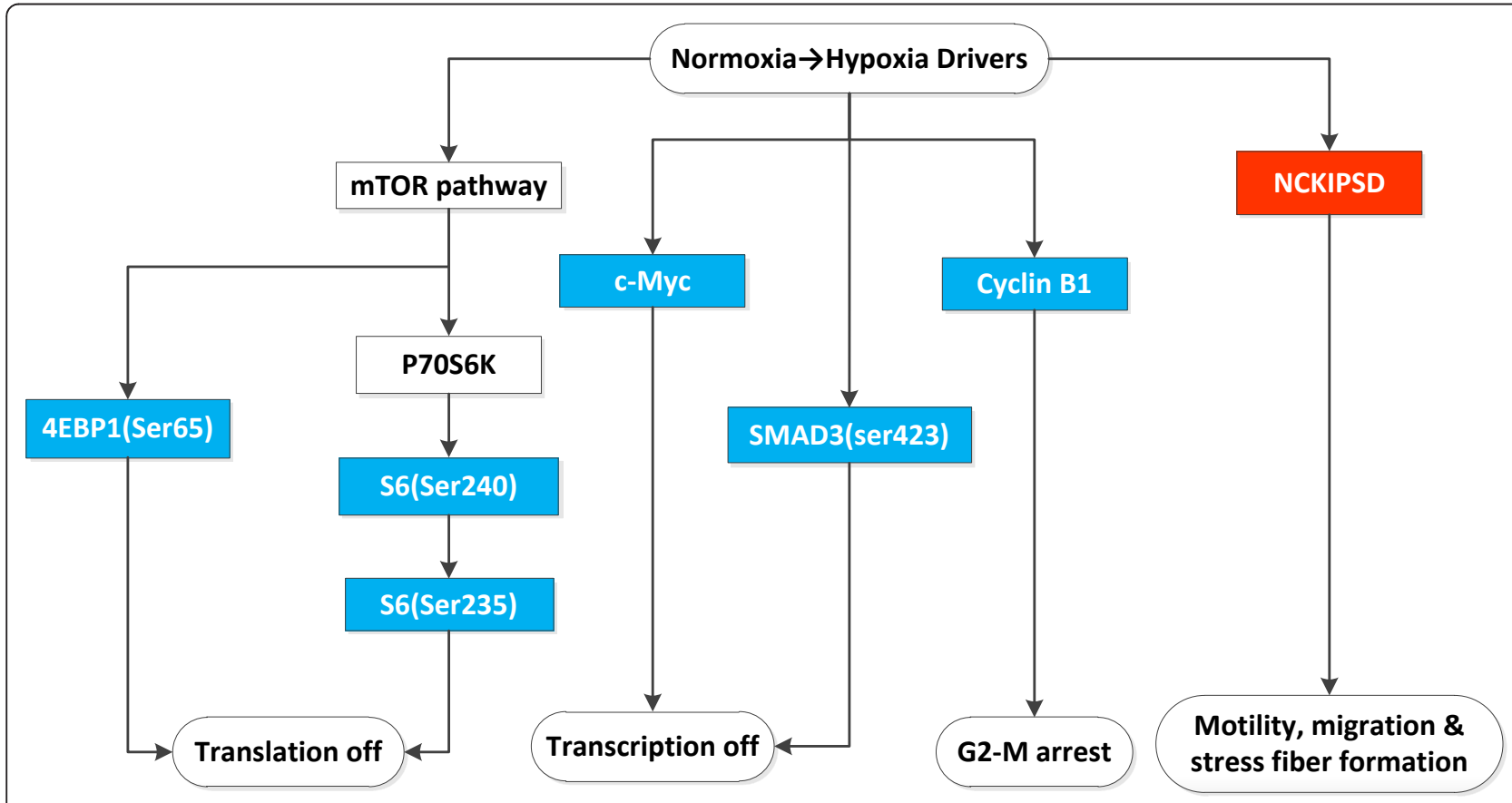

Figure 6 This is a cartoon of the partial shared pathways involved in the transition of $>50 \%$ of glioma and adenocarcinoma cell lines from normoxia to hypoxia. The red color indicates the protein increased and the blue color that the protein decreased. 


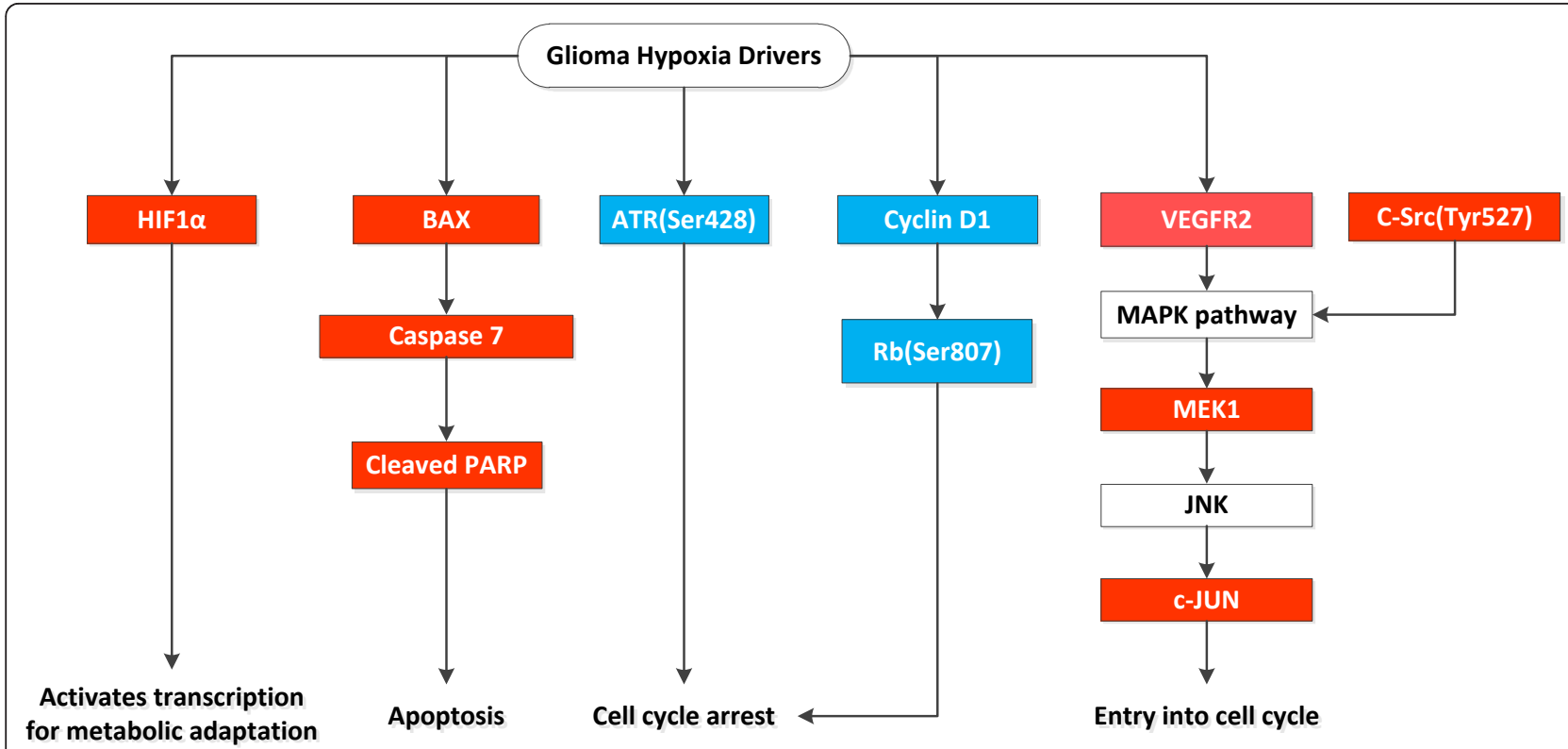

Figure 7 This is a cartoon of the partial pathways involved in the transition of $>50 \%$ of glioma cell lines from normoxia to hypoxia The red color indicates the protein increased and the blue color that the protein decreased.

Collection (Manassas, VA). Five high-grade glioma lines were comprised of U87, U251HF, and SNB19, bought from the American Type Culture Collection, and LNZ308 and LN229, gifts from Oliver Bogler (MD Anderson). Cells were maintained in Dulbecco's modified Eagle's medium: nutrient mixture F-12 (DMEM/F-12; Invitrogen, Carlsbad, CA) supplemented with10\% fetal bovine serum (Sigma-Aldrich, St. Louis, MO) and 1\% penicillin-streptomycin antibiotic (Invitrogen).

\section{Normoxia and Relative Hypoxia Conditions}

For normoxia experiments, 2D and 3D cultured cells were incubated in a humidified incubator with constant supply of $5 \% \mathrm{CO} 2$ at $37^{\circ} \mathrm{C}$ (21\% oxygen). $2 \mathrm{D}$ and $3 \mathrm{D}$ cultures were grown under conditions of relative hypoxia using the Incubator Subchamber Culture System with the ProOx 110 oxygen controller (BioSpherix, Lacona, NY) that senses oxygen inside the chamber and maintains it at the set level that was, in our experiments, $1 \%$ oxygen for relative hypoxia (for 24 hours).

\section{Antibodies and Validation}

The antibodies used are listed in Additional file 3, Table S1. To ensure that our antibodies were of sufficient quality, we used a denatured protein array and confirmed the specificity of the antibodies using Western blotting. Antibodies with only a single or dominant band on Western blotting were further assessed by direct comparison with RPPA using cell lines for differential protein expression, or they were modulated with ligands/inhibitors or siRNA for phosphoproteins or structural proteins, respectively. Only antibodies with Pearson correlations $>0.7$ between RPPA and Western blotting were considered "validated" and used in this RPPA study. Antibodies were further assessed for specificity and quantification using phosphopeptides and non-phosphopeptides arrayed on nitrocellulose-coated slides; those with a second non-dominant band that could be rationalized and were otherwise consistent in terms of RPPA linearity they were used "with caution." As can be appreciated from the Numerical Preprocessing section below, the original study was initiated with 187 proteins to cover a large part of the known proteome, but because of technical issues, we were only able to study 121 different proteins in the RRPA.

\section{Preparation of Cell Lysates}

The techniques used for the $2 \mathrm{D}$ studies were similar to those published previously $[1,36]$, however, the isolation of cells from the 3D medium is described in detail here.

\section{D Studies}

Briefly, less than $10^{6}$ cells $/ \mathrm{mL}$ were plated in flasks, harvested in exponential growth at about $80 \%$ confluence, and harvested using $0.25 \%$ trypsin. Cells were counted with a Vi-Cell Counter (Beckman Coulter, Brea, CA), and $5 \times 10^{6}$ cells were transferred to six-well plates (35$\mathrm{mm}$ diameter, $5-\mathrm{ml}$ volume) that were grown for $24 \mathrm{~h}$ at $37^{\circ} \mathrm{C}$ in $5 \% \mathrm{CO}_{2}$ and $20 \% \mathrm{O}_{2}$ [1]. Cells were similarly cultured in parallel for $24 \mathrm{~h}$ in a $1 \% \mathrm{O}_{2}$ hypoxic environment. Duplicate cultures were performed for each treatment. After $24 \mathrm{~h}$, cells were washed in phosphatebuffered saline and lysed in 1\% Triton X-100, $50 \mathrm{nM}$ 
HEPES (pH 7.4), $150 \mathrm{mM} \mathrm{NaCl}, 1.5 \mathrm{mM} \mathrm{MgCl} 2,1 \mathrm{mM}$ EGTA, $100 \mathrm{mM} \mathrm{NaF}, 10 \mathrm{mM}$ sodium pyrophosphate, 1 $\mathrm{mM} \mathrm{Na} \mathrm{NO}_{4}$, and $10 \%$ glycerol containing freshly added protease and phosphatase inhibitors. Cellular proteins were denatured by $1 \%$ sodium dodecyl sulfate (with $\beta$ mercaptoethanol) and diluted in five serial 1:2 dilution steps using dilution buffer (lysis buffer containing 1\% sodium dodecyl sulfate).

\section{$3 D$ Studies}

We used the AlgiMatrix 3D Culture System six-well kit (Invitrogen), which is an animal origin-free bioscaffold that facilitates 3D cell culture. $2 \times 10^{4}$ cells in exponential growth were pipetted into six-well plates in $5 \mathrm{~mL}$ of medium (DMEM/F-12) and inoculated directly into the sterile microtiter plates preloaded with lyophilized alginate sponge that had been formulated using USP-grade raw material from brown seaweed, and each plate incubated at $37^{\circ} \mathrm{C}$ in an atmosphere of $5 \% \mathrm{CO}_{2}$ and $20 \% \mathrm{O}_{2}$ (i.e., normoxia) to allow the cells to form spheroids. The cell lines grew similarly except for the ovarian cancer cell lines that grew a bit slower.

On day 5 , we transferred half the plates to the hypoxia chamber mentioned earlier and allowed them to grow for $24 \mathrm{~h}$ in relative hypoxia while the remaining half served as normoxia controls. To harvest spheroids after $24 \mathrm{~h}$ of hypoxia (i.e., on day 6), we followed the trisodium method described in the AlgiMatrix protocol. Briefly, $5 \mathrm{~mL}$ of pre-warmed iso-osmolar tri-sodium citrate solution was added to each well and incubated for $10 \mathrm{~min}$ at $37^{\circ} \mathrm{C}$. The solution was prepared by diluting $55 \mathrm{mM}$ tri-sodium citrate solution from $1 \mathrm{M}$ stock solution, adding $1 \mathrm{~g} / \mathrm{L}$ glucose, adjusting the osmolarity using $100 \mathrm{~g} / \mathrm{L} \mathrm{NaCl}$ solution, and adjusting the $\mathrm{pH}$ with $1 \mathrm{M}$ citric acid solution to a $\mathrm{pH}$ of 7.2-7.4. After 10 $\mathrm{min}$, the sponge biodegraded into the solution and the contents of each well was pipetted into a $15-\mathrm{mL}$ centrifuge tube. To the tube, $5 \mathrm{~mL}$ of the same tri-sodium citrate solution was added, and the mixture was centrifuged for $7 \mathrm{~min}$ at $400 \times \mathrm{g}$. The supernatant was removed, the pellet washed in phosphate-buffered saline to remove any remaining medium, and the pellet lysed using lysis buffer. The sample was then denatured, serially diluted, and arrayed on slides as in the 2D studies.

We manually isolated spheroids and determined the viability of single cells by adding them to $2 \mathrm{~mL}$ of trypsin-EDTA in a $15-\mathrm{mL}$ tube, incubating at $37^{\circ} \mathrm{C}$ for a few minutes, agitating the tube for 15-20 min, and counting using the Vi-Cell cell viability analyzer (Beckman-Coulter). In all cases, the proportion of viable cells was greater than $90 \%$.

\section{Array Assembly and Printing}

Array assembly and printing were done as previously described. [37] In addition to the sample spots (2D normoxia, 2D hypoxia, 3D normoxia, and 3D hypoxia samples), each slide also included spots corresponding to positive and negative controls prepared from mixed cell lysates and dilution buffer, respectively. For quantification, protein lysates were passed through five serial 1:2 dilution steps, spotted in triplicate, and arrayed in 384well plates (Genetix, Boston, MA). Samples were printed onto nitrocellulose-coated glass slides (FAST Slides, Schleicher \& Schuell BioScience, Inc. USA, Keene, NH) using an Aushon BioSystems 2470 Arrayer (Aushon BioSystems, Inc., Burlington, MA) with $175-\mu \mathrm{m}$ pins and a soft-touch deposition technology. For each triple, one series was located in the middle of the array and the other two were split on both sides and arranged in the reverse orientation, allowing us to estimate and correct for any spatial trends in intensity. To correct for staining, background, and loading variation across (array) slides, a positive control (a mixture of 12 cell lines hereafter called the "pooled control") and a lysate buffer negative control were printed at the end of each cell line sample row, creating a grid across the whole slide.

\section{Antibody Detection and Array Staining}

Antibody and array staining were done as previously described $[37,38]$. Briefly, slides were probed with primary antibody plus a biotin-conjugated secondary antibody. The signal was amplified using a DakoCytomationcatalyzed system (Dako, Copenhagen, Denmark) and visualized by the diaminobenzidine colorimetric reaction. Slides were incubated for $15 \mathrm{~min}$ in biotin-blocking solution to block endogenous peroxidase, avidin, and biotin prior to incubating slides in protein block at $4^{\circ} \mathrm{C}$ overnight. Primary antibodies in concentrations from 1:100 to 1:2000 were added to the slides and allowed to remain for 1-2 $\mathrm{h}$ with frequent slide agitation to insure mixing on the slide (see supplement table S-1 for dilutions and manufacturers of antibodies). A biotinylated secondary antibody (anti-mouse or -rabbit), diluted 1:10000-1:20000 and used as a starting point for signal amplification, was added and allowed to remain in contact with the cells for $1 \mathrm{~h}$. Subsequently, array slides were incubated using the Dako Signal Amplification System using a catalyzed reporter deposition of substrate to amplify the signal of the primary antibody. Slides were incubated in streptavidin-biotin-peroxidase and biotinyl tyramide/hydrogen peroxide reagents for 15 min each with washing in between the two incubations; 3,3'-diaminobenzidine tetrachloride was cleaved by tyramide-bound horseradish peroxidase, giving a stable brown precipitate.

\section{Analysis of RPPA Data Experimental Design and Deviations}

We studied 11 cell lines with two replicates under the four growth conditions resulting from combining $2 \mathrm{D}$ 
and 3D under normoxia and relative hypoxia, which would have ideally yielded 88 samples for measurement. Unfortunately, because of technical problems, there was only one replicate for LNZ308 in 3D under normoxia and hypoxia and one replicate for U87 in 3D in normoxia. Thus, we studied only 85 samples. Fortunately, the 41 pairs of exact replicates that did work are adequate to let us estimate the scale of technical variation, which is much smaller (variance 0.0053) than the variance 0.4615 for the cell line, growth condition, and treatment effects studied. Consequently, the replicate to replicate variation is sufficiently small and stable across our experiments relative to other sources of error that keeping the small number of samples without replicates will not lead to any distortion of the data.

\section{Numerical Preprocessing}

These samples were examined using 187 antibodies in RPPAs produced by the lead author's laboratory. Array images were produced using ImageQuant software (GE Healthcare, Waukesha, WI), and individual spot values were summarized using the MicroVigene RPPA module (VigeneTech, Carlisle, MA). After preprocessing was done, we used the $\mathrm{R}$ package SuperCurve (available at http://bioinformatics.mdanderson.org/Software/ OOMPA) to summarize each five-step dilution series into one $\log _{2}$ scale $\left(E C_{50}\right)$ protein concentration value. The algorithm used fits a joint four-parameter logistic model [39]. Values for 153 of these arrays passed signalto-noise filters assessed on control samples, giving the 85-by-153 data matrix we received from the core facility. Rows of this matrix (samples) were centered on the median to adjust for potential differences in sample loading. Correlations between replicate spotting's of the same samples on each array were also checked for consistency; we retained only the 124 (121 different proteins with 3 duplicates listed by different names) that showed correlations in excess of 0.5. Clustering and other exploratory data analysis showed that labels for samples 63 (MDA468-3D Hypoxia) and 83 (MDA231-3D Hypoxia) had accidentally been swapped; we corrected this.

\section{Statistical Analysis}

We used three-way ANOVAs, protein by protein, to model the $\log _{2}$ expression values produced by the RPPAs. We included terms for treatment (hypoxia or normoxia), growth conditions (2D or $3 \mathrm{D}$ ), and cell line of origin. We also included a term to account for potential interaction between treatment and medium.

To account for multiple testing, we fit distributions of p-values for each contrast with beta-uniform mixture (BUM) models ${ }^{5}$ and chose cutoffs to target false discovery rates (FDRs) of $5 \%$ and $1 \%$.

To determine what changes were "robust," we trichotomized residual terms for each effect (after correcting for others) by assigning scores of 1 (top 25\%), -1 (bottom $25 \%$ ), and 0 (all others), and summed these values by cell line or antibody, which is an approach we found useful in an earlier study [1]. We also used these sums to look for differences between gliomas and adenocarcinomas. Full details of our analyses (including data and code) are available from http://bioinformatics.mdanderson.org/Supplements/LevinHypoxia/

\section{Additional material}

Additional file 1: This file contains is from the quantile matrix of trichotomized values for 3D-2D values used in Figures 2 and 3 of the paper.

Additional file 2: This file contains is from the quantile matrix of trichotomized values for hypoxia-normoxia values used in Figure 4 of the paper.

Additional file 3: Table S1. Descriptions of 121 Distinct and 3 Duplicate Antibodies Used in Our RPPA Studies. BCL-XL, collagen VI, and Src (Tyr416/418), were used in duplicate, bringing the total number of antibodies studied in the RPPA to 124. Phosphorylation sites are indicated in parentheses.

\section{Acknowledgements}

The authors thank Kathryn Carnes and John McCool for editorial assistance and David Feith, Ph.D. (Pennsylvania State University College of Medicine) for hSAMDC and Spermine-synthase antibodies. Funding of this work was provided in part by the Greenspun Fund for Neuro-Oncology, the Alan Gold Memorial Fund for Brain Tumor Research, the Bernard W. Beidenharn Chair in Cancer Research, and NCl Core Grant CA16672.

\section{Author details}

${ }^{1}$ Department of Neuro-Oncology, The University of Texas MD Anderson Cancer Center, Houston, TX, USA. ${ }^{2}$ Department of Bioinformatics and Computational Biology, The University of Texas MD Anderson Cancer Center, Houston, TX, USA.

\section{Authors' contributions}

VAL conceived of the project, obtained funding for the research, and was the primary author. SP was the post-doctoral student who conducted the main aspects of the study and helped write the paper. KAB and LS did the RPPA analyses and the statistical portions of this study. KAB also helped write the paper. All authors approved the final manuscript.

\section{Competing interests}

The authors declare that they have no competing interests.

Received: 29 August 2011 Accepted: 25 January 2012 Published: 25 January 2012

\section{References}

1. Levin VA, Panchabhai SC, Shen L, Kornblau SM, Qiu Y, Baggerly KA: Different changes in protein and phosphoprotein levels result from serum starvation of high-grade glioma and adenocarcinoma cell lines. J Proteome Res 2010, 9(1):179-191.

2. Höckel M, Vaupel P: Tumor Hypoxia: Definitions and Current Clinical, Biologic, and Molecular Aspects. J Natl Cancer Inst 2001, 93(4):266-276.

3. Sutherland R, Freyer J, Mueller-Klieser W, Wilson R, Heacock C, Sciandra J, Sordat B: Cellular growth and metabolic adaptations to nutrient stress environments in tumor microregions. Int J Radiat Oncol Biol Phys 1986, 12(4):611-615.

4. Fodale $\mathrm{V}$, Pierobon $\mathrm{M}$, Liotta $\mathrm{L}$, Petricoin $\mathrm{E}$ : Mechanism of cell adaptation: when and how do cancer cells develop chemoresistance? CANCER JOURNAL 2011, 17(2):89-95. 
5. Fang JS, Gillies RD, Gatenby RA: Adaptation to hypoxia and acidosis in carcinogenesis and tumor progression. Seminars in cancer biology 2008, 18(5):330-337.

6. Malaise EP, Fertil B, Chavaudra N, Guichard M: Distribution of radiation sensitivities for human tumor cells of specific histological types: comparison of in vitro to in vivo data. Int J Radiat Oncol Biol Phys 1986, 12(4):617-624

7. Coleman CN: Hypoxia in tumors: a paradigm for the approach to biochemical and physiologic heterogeneity. J Natl Cancer Inst 1988, 80(5):310-317

8. Yamada KM, Cukierman E: Modeling tissue morphogenesis and cancer in 3D. Cell 2007, 130(4):601-610

9. Kim JB: Three-dimensional tissue culture models in cancer biology. Seminars in cancer biology 2005, 15(5):365-377.

10. Pampaloni $F$, Reynaud EG, Stelzer EH: The third dimension bridges the gap between cell culture and live tissue. Nature reviews Molecular cell biology 2007, 8(10):839-845

11. Horning JL, Sahoo SK, Vijayaraghavalu S, Dimitrijevic S, Vasir JK, Jain TK, Panda AK, Labhasetwar V: 3-D tumor model for in vitro evaluation of anticancer drugs. Molecular pharmaceutics 2008, 5(5):849-862.

12. Durand RE, Olive PL: Resistance of tumor cells to chemo- and radiotherapy modulated by the three-dimensional architecture of solid tumors and spheroids. In Methods in Cell Biology. Volume 64. Edited by: Darzynkiewicz Z, Crissman HA, Robinson JP. San Diego: Academic Press Inc; 2001:211-233.

13. Sminia $P$, Acker H, Eikesdal HP, Kaaijk P, Enger $P$, Slotman B, Bjerkvig R: Oxygenation and response to irradiation of organotypic multicellular spheroids of human glioma. Anticancer Res 2003, 23(2B):1461-1466.

14. Terzis AJ, Dietze A, Bjerkvig R, Arnold H: Effects of photodynamic therapy on glioma spheroids. Br J Neurosurg 1997, 11(3):196-205.

15. Sutherland RM, Sordat B, Bamat J, Gabbert H, Bourrat B, Mueller-Klieser W: Oxygenation and differentiation in multicellular spheroids of human colon carcinoma. Cancer Res 1986, 46(10):5320-5329.

16. Freyer JP, Sutherland RM: Proliferative and clonogenic heterogeneity of cells from EMT6/Ro multicellular spheroids induced by the glucose and oxygen supply. Cancer Res 1986, 46(7):3513-3520.

17. Chapman JD: Measurement of tumor hypoxia by invasive and noninvasive procedures: a review of recent clinical studies. Radiotherapy and oncology: journal of the European Society for Therapeutic Radiology and Oncology 1991, 20(Suppl 1):13-19.

18. Vaupel $P$, Schlenger $K$, Knoop C, Hockel M: Oxygenation of human tumors: evaluation of tissue oxygen distribution in breast cancers by computerized O2 tension measurements. Cancer Res 1991. 51(12):3316-3322.

19. Kunz M, Ibrahim SM: Molecular responses to hypoxia in tumor cells. Mol Cancer 2003, 2:23.

20. Harris AL: Hypoxia-a key regulatory factor in tumour growth. Nature reviews Cancer 2002, 2(1):38-47.

21. Koh MY, Darnay BG, Powis G: Hypoxia-associated factor, a novel E3ubiquitin ligase, binds and ubiquitinates hypoxia-inducible factor 1alpha, leading to its oxygen-independent degradation. Mol Cell Biol 2008, 28(23):7081-7095.

22. Sano K, Hayakawa A, Piao JH, Kosaka Y, Nakamura H: Novel SH3 protein encoded by the AF3p21 gene is fused to the mixed lineage leukemia protein in a therapy-related leukemia with $t(3 ; 11)$ (p21;q23). Blood 2000 95(3):1066-1068.

23. Fukuoka M, Suetsugu S, Miki H, Fukami K, Endo T, Takenawa T: A novel neural Wiskott-Aldrich syndrome protein (N-WASP) binding protein, WISH, induces Arp2/3 complex activation independent of Cdc42. J Cell Biol 2001, 152(3):471-482

24. Lim CS, Kim SH, Jung JG, Kim JK, Song WK: Regulation of SPIN90 phosphorylation and interaction with Nck by ERK and cell adhesion. J Biol Chem 2003, 278(52):52116-52123.

25. Ronty M, Taivainen A, Heiska L, Otey C, Ehler E, Song WK, Carpen O: Palladin interacts with SH3 domains of SPIN90 and SrC and is required for Src-induced cytoskeletal remodeling. Exp Cell Res 2007, 313(12):2575-2585.

26. Kim Y, Chang S: Ever-expanding network of dynamin-interacting proteins. Mol Neurobiol 2006, 34(2):129-136.

27. Kim DJ, Kim SH, Lim CS, Choi KY, Park CS, Sung BH, Yeo MG, Chang S, Kim JK, Song WK: Interaction of SPIN90 with the Arp2/3 complex mediates lamellipodia and actin comet tail formation. J Bio/ Chem 2006, 281(1):617-625.

28. Mendez O, Zavadil J, Esencay M, Lukyanov Y, Santovasi D, Wang SC, Newcomb EW, Zagzag D: Knock down of HIF-1alpha in glioma cells reduces migration in vitro and invasion in vivo and impairs their ability to form tumor spheres. Mol Cancer 2010, 9:133.

29. Zagzag D, Esencay M, Mendez O, Yee H, Smirnova I, Huang Y, Chiriboga L, Lukyanov E, Liu M, Newcomb EW: Hypoxia- and vascular endothelial growth factor-induced stromal cell-derived factor-1alpha/CXCR4 expression in glioblastomas: one plausible explanation of Scherer's structures. Am J Pathol 2008, 173(2):545-560.

30. Zagzag D, Lukyanov Y, Lan L, Ali MA, Esencay M, Mendez O, Yee H, Voura EB, Newcomb EW: Hypoxia-inducible factor 1 and VEGF upregulate CXCR4 in glioblastoma: implications for angiogenesis and glioma cell invasion. Lab Invest 2006, 86(12):1221-1232.

31. Wouters $B G$, Koritzinsky M: Hypoxia signalling through mTOR and the unfolded protein response in cancer. Nature reviews Cancer 2008, 8(11):851-864.

32. Kreisl TN, Lassman AB, Mischel PS, Rosen N, Scher HI, Teruya-Feldstein J, Shaffer D, Lis E, Abrey LE: A pilot study of everolimus and gefitinib in the treatment of recurrent glioblastoma (GBM). J Neurooncol 2009, 92(1):99-105.

33. Cloughesy TF, Yoshimoto K, Nghiemphu P, Brown K, Dang J, Zhu S, Hsueh T, Chen Y, Wang W, Youngkin D, et al: Antitumor activity of rapamycin in a Phase I trial for patients with recurrent PTEN-deficient glioblastoma. PLoS Med 2008, 5(1):e8.

34. Galanis E, Buckner JC, Maurer MJ, Kreisberg Jl, Ballman K, Boni J, Peralba JM Jenkins RB, Dakhil SR, Morton RF, et al: Phase II trial of temsirolimus (CCl779) in recurrent glioblastoma multiforme: a North Central Cancer Treatment Group Study. J Clin Oncol 2005, 23(23):5294-5304.

35. Chang SM, Wen P, Cloughesy T, Greenberg H, Schiff D, Conrad C, Fink K, Robins HI, De Angelis L, Raizer J, et al: Phase II study of CCI-779 in patients with recurrent glioblastoma multiforme. Invest New Drugs 2005 23(4):357-361.

36. Levin VA, Tada K, Mircean C: Lysate Array Analyses of Signal Transduction Inhibitors in Tumor Cell Lines. Clin Proteomics 2006, 2:33-44.

37. Kornblau SM, Tibes R, Qiu Y, Chen W, Kantarjian HM, Andreeff M, Coombes KR, Mills GB: Functional proteomic profiling of AML predicts response and survival. Blood 2008, blood-2007-2010-119438.

38. Tibes R, Qiu Y, Lu Y, Hennessy B, Andreeff M, Mills GB, Kornblau SM: Reverse phase protein array: validation of a novel proteomic technology and utility for analysis of primary leukemia specimens and hematopoietic stem cells. Mol Cancer Ther 2006, 5(10):2512-2521.

39. Hu J, He X, Baggerly KA, Coombes KR, Hennessy BT, Mills GB: Nonparametric quantification of protein lysate arrays. Bioinformatics 2007, 23(15):1986-1994.

doi:10.1186/1477-5956-10-5

Cite this article as: Levin et al:: Protein and phosphoprotein levels in glioma and adenocarcinoma cell lines grown in normoxia and hypoxia in monolayer and three-dimensional cultures. Proteome Science 2012 10:5

\section{Submit your next manuscript to BioMed Central and take full advantage of:}

- Convenient online submission

- Thorough peer review

- No space constraints or color figure charges

- Immediate publication on acceptance

- Inclusion in PubMed, CAS, Scopus and Google Scholar

- Research which is freely available for redistribution

Submit your manuscript at www.biomedcentral.com/submit
C Biomed Central 